\title{
El gran salto: De vendedor a supervisor
}

\section{The big jump: From seller to supervisor}

Ec. Mario Paz y Miño Phillips, MBA

Universidad Internacional del Ecuador, Ecuador

Autor para correspondencia: mario_pazymino@yahoo.com.ar

Fecha de recepción: 15 de Febrero de 2016 - Fecha de aceptación: 20 de Mayo de 2016

\section{Resumen}

El presente documento intenta analizar los factores críticos de éxito que deben tomarse en cuenta ante el paso de un ejecutivo de ventas desde cargos de primera línea a mandos medios soportado en exposiciones y/o investigaciones de varios autores sobre temas de Ventas, Liderazgo y manejo de equipos.

Palabras claves: ventas; liderazgo; empoderar; comunicar; trabajo de equipo

\begin{abstract}
This paper aims to analyze the critical success factors that must be considered before the transition of a salesperson from frontline positions to middle management, supported in papers, books or essays of several authors on topics of Sales, Leadership and team management.
\end{abstract}

Key words: sales; leadership; empowerment; communication; teamwork 


\section{Introducción}

Por años los vendedores entiéndase los ejecutivos de ventas, asesores o gestores comerciales fueron los encargados de transformar piedras en oro, de dar el toque de Rey Midas. Por supuesto eso en tiempos en que el mercado era dominado por los productores, donde la calidad estaba subvalorada, la innovación era escasa y la tecnología era precaria. En los últimos 20 años donde estos factores cambiaron, entonces el rol del vendedor cambió. Hoy el vendedor profesional a cualquier nivel debe tener conocimientos básicos de marketing, desarrollar su orientación al cliente, alimentar sus redes de contactos, cultivar su habilidad de escucha, lograr niveles importantes de empatía y ser abierto a los cambios. Tal como señala Jobber y Lancaster (2012) las ventas se consideran como parte de la función de marketing. Entonces la estrategia para los vendedores se ha sofisticado desde el plan de marketing estratégico, es decir desde la segmentación, target y posicionamiento, estos reciben los primeros anuncios y orientaciones comerciales para la prospección y calificación de potenciales clientes. El proceso de venta dejó de ser salir a buscar convencer a un potencial cliente de adquirir un producto que no necesita, no desea y que difícilmente volvería a comprar

Pero y ¿qué sucede cuando el vendedor es talentoso, independiente, efectivo y ambicioso? ¿Qué hay después? Es posible se dé el salto de ese vendedor. Este pasa de ser un trabajador de primera línea a engrosar los mandos medios, deja una tarea individual y pasa a ejecutar tareas a través de otros, pasa de desarrollar clientes a desarrollar personas, de patrullar territorios, dar servicio, retener clientes a reclutar, seleccionar, entrenar y motivar subordinados, de jugador pasa a ser el coach, en definitiva pasa de vender a planificar. Entonces ¿qué desafíos grandes afronta el nuevo ejecutivo en este gigantesco salto? Se identifican ocho factores claves de éxito en que debemos centrar el paso de un funcionario de primera línea a uno de mando medios que permitan desarrollar las nuevas funciones de ventas en la mejor forma posible.

Planificar y Dirigir.- Se debe considerar que es muy probable que el nuevo Supervisor, jefe o gerente ha sido seleccionado para el cargo luego de un reclutamiento, éste puede haber sido interno y/o externo. Cuando sucede lo primero éste nuevo ascenso le requerirá al nuevo elegido a dirigir a sus antiguos pares, lo que requerirá de poderosas y delicadas decisiones como dejar a ir a los inconformes y cabildear entre las piezas claves del nuevo equipo que está por conformar y dirigir. Estas decisiones son de carácter muy distinto a las de su antiguo cargo. Para Franchi (2010) el planear y dirigir implica definir primero los principios filosóficos esto es la misión y propósito estratégico del grupo. Posteriormente la estrategia competitiva, es decir el mercado en que se va a desempeñar el grupo o equipo de trabajo, analizando fortalezas, debilidades, oportunidades y amenazas y finalmente la estrategia operativa, esto es las políticas y procedimientos ligados al trabajo, en términos más claros "el marcado de la cancha". Organizar la fuerza de ventas.- La organización de la estructura de la fuerza de ventas es una decisión importante dentro de la agenda del nuevo ejecutivo. Éste debe decidir si mantenerla, modificarla parcial o totalmente

Retomando a Jobber y Lancaster (2012) ellos distinguen entre las principales y más conocidas:

1) Estructura geográfica, el nivel de gerente de área es opcional: cuando el Número de representantes de ventas (alcance de control) por debajo de cada gerente regional excede de ocho, debe considerarse seriamente la asignación de gerentes de área. 
2) Estructura de especialización de productos; La gestión de ventas pasa de territorios a productos pudiendo en el futuro traslapar ambos factores hasta llevarlo a una especie de estructura matricial donde el reporte puede ser a los jefes por organización geográfica y de producto

3) Estructura basada en la industria o líneas de negocio;

4) Estructura de tamaño de cuenta. La organización de este estilo depende del tamaño de los clientes, este análisis parte de a través de una análisis de Pareto para determinar la nueva política de Administración de cuentas. Este formato ha dado paso a la creación del Key Account Manager (KAM)

Reclutar y seleccionar.- El nuevo ejecutivo a través de su red de contactos debe ser capaz de reclutar y seleccionar miembros clave calificados para la formación de su nuevo equipo, por lo tanto orientar su red de contactos de una manera distinta a la que venía haciendo. Ya no sólo busca contactos para encontrar prospectos sino también para encontrar potenciales miembros de su equipo de trabajo. De esta manera mantener una activa participación en este subproceso asignado tradicionalmente a las áreas de Recursos Humanos pero de alto impacto en los resultados de un equipo de Ventas.

Capacitar.- Es tal vez una de las tareas más duras pero a la vez más gratificantes. Capacitar no sólo significa conocer de los productos y procesos significa poderlos transmitir. Para Karl Albrecht (2004) la jerarquía del conocimiento se da desde manejar datos e información, al involucrarse con la información generar conocimiento, y al añadirle perspectiva y alineación estratégica se transforma en sabiduría. Sólo a estos niveles el nuevo ejecutivo podrá transmitir su conocimiento y sabiduría desde varios puntos de vista a su equipo de trabajo.

Empoderar.- El cliché "Si quieres que esté bien hecho debes hacerlo tú mismo" es el peor consejo que los nuevos líderes pueden tomar, esto se puede dar por su arraigo a sus antiguas tareas. La respuesta está el empoderamiento que según Blanchard (2006) significa darles facultades a los subordinados para que tomen decisiones de acuerdo a sus conocimientos sin esperar la toma de decisiones de sus superiores. Resulta lógico pensar que para empoderar debemos formar, capacitar, dar autoridad y principalmente responsabilizarnos por los resultados que el otorgar esa facultad a un tercero conlleve.

Comunicar.- Para Cámara y Sanz (2001) la comunicación debe tener una alta carga de asertividad centrada en la escucha activa más que en la clásica persuasión a los que los vendedores están acostumbradas a llevar a cabo. En la comunicación estos autores no sólo se centran en cómo nos comunicamos, sino también los comportamientos y el estilo de liderazgo que naturalmente el nuevo líder mantienen. Sólo reconociéndose cómo se comunica y se comporta es posible desarrollar las habilidades de comunicación.

Motivar.- Recojo lo que manifiestan Kouzes y Posner (2007) sobre la motivación. Entre las cinco prácticas comunes que identificaron en líderes fuera de la común encontraron "alentar el corazón". Estas prácticas relacionadas con la motivación pueden ser tan comunes como felicitar en público y reprender en privado. Reconocer los niveles de excelencia y premiar la iniciativa y proactividad más allá de los resultados y de un incentivo meramente económico. 
Facilitar el trabajo en equipo.- Para Schwarz (2013) un enfoque de aprendizaje mutuo por encima de un enfoque unilateral permite el desarrollo de equipos de alto desempeño. El autor nos provee de herramientas poderosas de cambio profundamente personal en primera instancia para luego transmitir un cambia de enfoque en del equipo.

Schwarz manifiesta cómo el enfoque unilateral mina la confianza de los miembros del equipo a hacer sugerencias, a participar activamente de las reuniones de grupo, a proponer soluciones innovadoras, etc. Esto se da por los valores y supuestos que el enfoque unilateral mantiene para posteriormente observar comportamientos en el líder como por ejemplo:

- Imponer el punto de vista personal sin consultar el de otros miembros

- Retener información clave para la toma de decisiones

- Enfocarse en posiciones no en intereses

- Actuar sobre supuestos que no han sido probados y que son parte de una vivencia personal, sólo la del líder.

- Controlar totalmente la conversación y el desarrollo de las ideas

Para el autor el enfoque de aprendizaje mutuo tienen como resultado comportamientos totalmente opuestos al enfoque unilateral basado en un cambio en los supuestos y valores que posteriormente emerjan en comportamientos y finalmente en efectos dentro del equipo de trabajo.

\section{Conclusiones}

Si bien hay más factores a tener en cuenta por el nuevo ejecutivo como por ejemplo la remuneración de su equipo de ventas, los sistemas de control de resultados, definición de cuotas de venta, elaboración de presupuestos y reportería, estos en la práctica vienen ya diseñados en una organización regida por procesos establecidos, por lo tanto no han sido calificados como críticos. Se podría afirmar que un salto de este tipo depende mucho de habilidades humanas más que de habilidades técnicas. Es un cambio de mentalidad e involucra una alta carga de madurez e inteligencia emocional del recién promovido. Es todo un desafío para el nuevo ejecutivo, pero peor aún más para quiénes serán sus mentores o líderes en el nuevo cargo. Los factores críticos de éxitos que se han considerado son algunos de los retos a enfrentarse como un medio para la consecución de resultados propuestos.

\section{Bibliografía}

Albrecht, Karl: Hacia las culturas del conocimiento, en Gestión, Vol. 9, Nro. 2, 2004.

Blanchard, Ken: “Empowerment”, Editorial Norma, 1996.

Cámara, Dionisio; Sanz, María: "Dirección de Ventas". Vender y fidelizar en el nuevo milenio, Editorial Pearson Educación, 2001

Franchi, Roberto: “Organizaciones que viven y organizaciones que funcionan” Editorial Nobuko, 2010

Jobber, David y Lancaster Geoffrey: “Administración de Ventas” 8va Edición Editorial Pearson, 2012

Kouzes James M y Posner Barry Z: “El desafío del liderazgo” Editorial Granica 1997

Schwarz Roger, Smart leaders, smarter teams: how you and your team get unstuck to get results, Jossey Bass, 2013 